University of Wollongong

Research Online

Faculty of Engineering and Information

Faculty of Engineering and Information

Sciences - Papers: Part A

Sciences

$1-1-2015$

Effects of salinity build-up on biomass characteristics and trace organic chemical removal: Implications on the development of high retention membrane bioreactors

\author{
Wenhai Luo \\ University of Wollongong,wl344@uowmail.edu.au \\ Faisal I. Hai \\ University of Wollongong, faisal@uow.edu.au \\ Jinguo Kang \\ University of Wollongong, jkang@uow.edu.au \\ William E. Price \\ University of Wollongong, wprice@uow.edu.au \\ Wenshan Guo \\ University of Technology Sydney
}

See next page for additional authors

Follow this and additional works at: https://ro.uow.edu.au/eispapers

Part of the Engineering Commons, and the Science and Technology Studies Commons

Research Online is the open access institutional repository for the University of Wollongong. For further information contact the UOW Library: research-pubs@uow.edu.au 


\title{
Effects of salinity build-up on biomass characteristics and trace organic chemical removal: Implications on the development of high retention membrane bioreactors
}

\author{
Abstract \\ This study investigated the impact of salinity build-up on the performance of membrane bioreactor (MBR), \\ specifically in terms of the removal and fate of trace organic chemicals (TrOCs), nutrient removal, and \\ biomass characteristics. Stepwise increase of the influent salinity, simulating salinity build-up in high \\ retention MBRs, adversely affected the metabolic activity in the bioreactor, thereby reducing organic and \\ nutrient removal. The removal of hydrophilic TrOCs by MBR decreased due to salinity build-up. By \\ contrast, with the exception of $17 \alpha$-ethynylestradiol, the removal of all hydrophobic TrOCs was not \\ affected at high salinity. Moreover, salinity build-up had negligible impact on the residual accumulation of \\ TrOCs in the sludge phase except for a few hydrophilic compounds. Additionally, the response of the \\ biomass to salinity stress also dramatically enhanced the release of both soluble microbial products \\ (SMP) and extracellular polymeric substances (EPS), leading to severe membrane fouling.

\section{Disciplines \\ Engineering | Science and Technology Studies}

\section{Publication Details} \\ Luo, W., Hai, F. I., Kang, J., Price, W. E., Guo, W., Ngo, H. H., Yamamoto, K. \& Nghiem, L. D. (2015). Effects of \\ salinity build-up on biomass characteristics and trace organic chemical removal: Implications on the \\ development of high retention membrane bioreactors. Bioresource Technology, 177 274-281.

\section{Authors} \\ Wenhai Luo, Faisal I. Hai, Jinguo Kang, William E. Price, Wenshan Guo, Hao H. Ngo, Kazuo Yamamoto, and \\ Long D. Nghiem
}




\section{RESEARCH HIGHLIGHTS}

o The removal of hydrophilic TrOCs by MBR decreased due to salinity build-up

o Organic carbon and nutrient removals by MBR decreased at elevated salinity

o High salinity had negligible impact on the removal of most hydrophobic TrOCs by MBR

o Fate of TrOCs in the sludge phase was not significantly affected by salinity

o High salinity condition accelerated membrane fouling due to SMP and EPS release 


\section{Effects of salinity build-up on biomass characteristics and trace organic chemical removal: Implications on the development of high retention membrane bioreactors}

\section{Bioresource Technology}

Wenhai Luo ${ }^{a}$, Faisal I. Hai ${ }^{a}$, Jinguo Kang ${ }^{b}$, William E. Price ${ }^{b}$, Wenshan Guo ${ }^{c}$, Hao H. $\mathrm{Ngo}^{\mathrm{c}}$, Kazuo Yamamoto ${ }^{\mathrm{d}}$, Long D. Nghiem ${ }^{{ }^{*}}$

${ }^{a}$ Strategic Water Infrastructure Laboratory, School of Civil Mining and Environmental Engineering, University of Wollongong, Wollongong, NSW 2522, Australia

${ }^{b}$ Strategic Water Infrastructure Laboratory, School of Chemistry, University of Wollongong, Wollongong, NSW 2522, Australia

${ }^{c}$ Centre for Technology in Water and Wastewater, School of Civil and Environmental Engineering, University of Technology Sydney, Sydney, NSW 2007, Australia

${ }^{d}$ Environmental Science Center, The University of Tokyo, Tokyo 113-0033, Japan

\footnotetext{
* Corresponding author: longn@uow.edu.au; Ph: +61 (2) 42214590.
} 


\begin{abstract}
This study investigated the impact of salinity build-up on the performance of membrane bioreactor (MBR), specifically in terms of the removal and fate of trace organic chemicals (TrOCs), nutrient removal, and biomass characteristics. Stepwise increase of the influent salinity, simulating salinity build-up in high retention MBRs, adversely affected the metabolic activity in the bioreactor, thereby reducing organic and nutrient removal. The removal of hydrophilic TrOCs by MBR decreased due to salinity build-up. By contrast, with the exception of $17 \alpha$-ethynylestradiol, the removal of all hydrophobic TrOCs was not affected at high salinity. Moreover, salinity build-up had negligible impact on the residual accumulation of TrOCs in the sludge phase except for a few hydrophilic compounds. Additionally, the response of the biomass to salinity stress also dramatically enhanced the release of both soluble microbial products and extracellular polymeric substances, leading to severe membrane fouling.
\end{abstract}

Keywords: Membrane bioreactor (MBR); Trace organic chemicals (TrOCs); Salinity buildup; Biomass characteristics; Wastewater treatment.

\title{
1. Introduction
}

Fresh water scarcity in many parts of the world is a significant concern (Elimelech and Phillip, 2011). This issue is further exacerbated by population growth, urbanisation, environmental pollution, and climate change. As a result, over the last few decades, there have been many dedicated efforts to develop and improve treatment processes that utilize alternative water sources including wastewater in order to augment water supply and alleviate water stress. A notable treatment process is membrane bioreactor (MBR) which integrates membrane filtration with the conventional activated sludge (CAS) treatment technology. MBRs can offer a better quality effluent and a lower sludge production, but with a much smaller physical footprint in comparison to CAS processes (Hai et al., 2014). Thus, the MBR system has been widely recognised as a preferable alternative, especially in water reuse applications where high effluent quality is required.

The widespread occurrence of trace organic chemicals (TrOCs) in secondary treated effluent, such as pharmaceutically active chemicals and endocrine disrupting compounds, remains a 
vexing issue associated with wastewater treatment, particularly for potable water reuse applications (Tran et al., 2013; Luo et al., 2014b). MBR is typically operated using a longer sludge retention time (SRT). The mixed liquor suspended solids (MLSS) concentration in MBR is typically from $5-20 \mathrm{~g} / \mathrm{L}$, which is considerably higher than that in CAS (up to 4 g/L) (Hai et al., 2014). Thus, compared to CAS, MBR can provide an appreciable removal of certain TrOCs. However, several previous studies have demonstrated a remarkable variation in the removal of TrOCs, ranging from almost complete removal of certain chemicals (e.g. estradiol and ibuprofen) to negligible removal of several others (e.g. diclofenac and carbamazepine) (Hai et al., 2011; Tadkaew et al., 2011). Such a large variation was possibly due to the diverse physicochemical properties of TrOCs (Tadkaew et al., 2011). Additionally, the removal of TrOCs could also be significantly influenced by the operating conditions of MBRs, such as hydraulic and sludge retention times (Weiss and Reemtsma, 2008), temperature (Hai et al., 2011), and mixed liquor pH (Urase et al., 2005; Tadkaew et al., 2010).

Further developments of MBRs have resulted in the emergence of a novel high retention (HR)-MBR concept. Typical HR-MBRs include osmotic membrane bioreactor (OMBR) (Achilli et al., 2009), membrane distillation bioreactor (Phattaranawik et al., 2008), and nanofiltration membrane bioreactor (Choi et al., 2002). In these systems, forward osmosis, membrane distillation and nanofiltration are employed as the high retention membrane process. These membranes have high rejection capability and can effectively retain small and/or persistent TrOCs, thus prolonging their retention time in the bioreactors for further biodegradation. As a result, HR-MBRs can be considered as a reliable technique to produce high quality effluent for potable water reuse or direct effluent discharge in sensitive areas.

The rejection of colloidal particles and certain dissolved substances by high retention membranes allows HR-MBRs to produce high quality effluent. But, this can also result in the build-up of salinity in the bioreactor (Lay et al., 2010; Luo et al., 2014a). Salinity build-up is expected for all HR-MBR types but can be more severe for OMBRs due to the reverse diffusion of draw solutes. In addition, high and/or varying wastewater salinity also presents a challenge to biological treatment such as coastal sewers subjected to infiltration of seawater or discharges from individual high salinity processes (e.g. seafood and cheese manufactures). 
Moderate to high salinities can alter sludge characteristics and microbial community, thereby deteriorating MBR performance (Reid et al., 2006; Yogalakshmi and Joseph, 2010). Thus, understanding the impact of salinity build-up on the performance of the biological reactor and membrane fouling is essential for the development of HR-MBRs. It is also noteworthy that, to date, the impact of salinity build-up on the removal of TrOCs during either conventional MBR or HR-MBR treatment remains unclear.

This study aimed to investigate the effects of salinity build-up (up to $16.5 \mathrm{~g} \mathrm{NaCl} / \mathrm{L}$ ) on the removal of TrOCs and biomass properties during MBR treatment. These will have important implications for understanding and management of salinity build-up in HR-MBRs during wastewater treatment. The basic performance of MBR at elevated salinity was also examined in terms of organic and nutrient removals as well as membrane fouling propensity.

\section{Materials and methods}

\subsection{Trace organic chemicals}

A set of 31 TrOCs was selected in this study based on their widespread occurrence in raw sewage and/or sewage-impacted water bodies as well as their diverse physicochemical properties, such as hydrophobicity and molecular structure (Supplementary Data, Table S1). These compounds represent four major groups of chemicals of emerging concern, including pharmaceutical and personal care products, endocrine disrupting chemicals, pesticides, and industrial chemicals. A stock solution containing all 31 TrOCs was prepared in pure methanol at a concentration of $25 \mathrm{mg} / \mathrm{mL}$ of each chemical and stored at $-18{ }^{\circ} \mathrm{C}$ in the dark. The stock solution was used within less than a month or else discarded.

\subsection{MBR set-up}

In this study, two parallel lab-scale MBR systems, namely control- and saline-MBRs (Supplementary Data, Fig. S1), were continuously operated under identical operating conditions. Each system consisted of a glass reactor with effective volume of $5.7 \mathrm{~L}$ and housed a submerged hollow fibre microfiltration membrane module (SADF0790M mini module, Mitsubishi Rayon Engineering, Japan). The membrane was made of PVDF with a nominal pore size of $0.4 \mu \mathrm{m}$ and an effective surface area of $740 \mathrm{~cm}^{2}$. The reactors were placed in a temperature-controlled water bath which was equipped with an immersion PID 
regulated heating unit (Julabo, Germany). Two uniform electrical air pumps (Heilea, model ACO 012) were used to aerate the reactors via coarse bubble diffusers (Aqua One, Australia) located at the bottom of the reactors to supply enough dissolved oxygen, prevent sludge settlement and also to scour the membrane. The effluent peristaltic pumps (Masterflex L/S, USA) were controlled by a computer to operate the membrane modules in 14 min on and 1 min off cycles. This on/off cycle aimed to provide a relaxation time to the membrane modules. The flow rate of the influent peristaltic pumps (Masterflex L/S, USA) was matched with that of the effluent pumps to maintain a constant reactor volume. The trans-membrane pressure (TMP) was continuously monitored by a high resolution $( \pm 0.1 \mathrm{kPa})$ pressure sensor (Extech Equipment, Australia) as an indicator of membrane fouling.

\subsection{Experimental protocol}

Synthetic wastewater (Supplementary Data, Table S2) was used in this study to simulate medium strength municipal sewage and to maintain a stable influent condition. The MBR systems were seeded with activated sludge from the Wollongong Wastewater Treatment Plant (Wollongong, Australia). They were initially acclimatised for 30 days at a MLSS concentration of $5 \mathrm{~g} / \mathrm{L}$, temperature of $26.0 \pm 0.2^{\circ} \mathrm{C}$, dissolved oxygen concentration of $5 \pm 1$ $\mathrm{mg} / \mathrm{L}$, mixed liquor conductivity and $\mathrm{pH}$ of $260 \pm 27.9 \mu \mathrm{S} / \mathrm{cm}$ and $6.7 \pm 0.5$, respectively. The hydraulic retention time was maintained at 24 hours, corresponding to a constant permeate flux of $3.5 \mathrm{~L} / \mathrm{m}^{2} \mathrm{~h}$. Once the steady-state performance of the MBRs had been established, a stock solution containing 31 TrOCs was spiked into the synthetic wastewater every day to obtain a concentration of $5 \mu \mathrm{g} / \mathrm{L}$ for each compound. Both MBRs were operated for two weeks to achieve stable conditions with regard to TrOC removal and other performance before $\mathrm{NaCl}$ was added to the feed of the saline-MBR to simulate salinity buildup.

Salinity build-up was simulated by gradually increasing the concentration of $\mathrm{NaCl}$ in the saline-MBR from 0 to $16.5 \mathrm{~g} / \mathrm{L}$ with a salinity gradient of $0.5 \mathrm{~g} \mathrm{NaCl} / \mathrm{L}$ per day (Supplementary Data, Fig. S1). The maximum salinity was determined by modelling the steady-state salt accumulation in an OMBR system with a commercial cellulose triacetate forward osmosis membrane (Supplementary Data, Appendix A). To investigate the possible microbial adaptation to high salinity, the saline-MBR was operated for two weeks at the 
salinity loadings of 10 and $16.5 \mathrm{~g} \mathrm{NaCl} / \mathrm{L}$. Therefore, the saline-MBR was continuously operated for 70 days. By contrast, the control MBR system was operated under the same operating conditions without any $\mathrm{NaCl}$ addition. The weekly removal of some sludge for analysis resulted in an operating SRT of approximately 50 days. Membrane cleaning was conducted periodically by ex-situ backwashing with $1 \% \mathrm{NaOCl}$ for $20 \mathrm{~min}$, and then rinsing with deionized water.

\subsection{Analytical methods}

\subsubsection{Analysis of basic water quality parameters}

Total organic carbon (TOC) and total nitrogen (TN) were analysed using a TOC/TN- $\mathrm{V}_{\mathrm{CSH}}$ analyser (Shimadzu, Japan). Ammonium nitrogen $\left(\mathrm{NH}_{4}{ }^{+} \mathrm{N}\right)$ and phosphate $\left(\mathrm{PO}_{4}{ }^{3-}\right)$ were measured by a Flow Injection Analysis system (QuichChem 8500, Lachat, USA). The mixed liquor $\mathrm{pH}$ and conductivity were determined using an Orion 4-Star Plus $\mathrm{pH} /$ conductivity meter (Thermo Fisher Scientific, USA).

\subsubsection{Analysis of biomass characteristics}

Soluble microbial product (SMP) and extracellular polymeric substances (EPS) were extracted according to the thermal method reported by Zhang et al. (1999) and were normalized as the sum of protein and polysaccharide contents. The protein content was determined by the Folin method using bovine serum albumin as the standard. The polysaccharide content was measured based on the phenol-sulphuric acid method with glucose as the standard.

The specific oxygen uptake rate (SOUR) of the sludge was measured according to the technique described by Choi et al. (2007). The MLSS and mixed liquor volatile suspended solid (MLVSS) concentrations were determined based on the Standard Methods for the Examination of Water and Wastewater (APHA, 2005). The relative hydrophobicity of the sludge was determined by a MATH-test modified by Van den Broeck et al. (2011).

\subsubsection{Analysis of trace organic chemicals}

The influent and effluent TrOC concentrations were determined using an analytical method previously reported by Hai et al. (2011). This method consisted of the solid phased extraction 
(SPE), derivation, and quantitative determination by a gas chromatography-mass spectrometry (GC-MS) system (QP5000, Shimadzu, Japan). The removal efficiency during MBR treatment was calculated as:

$R(\%)=100 \times\left(1-\frac{C_{E f f}}{C_{I n f}}\right)$

where $C_{I n f}$ and $C_{E f f}$ are the influent and effluent TrOC concentrations, respectively.

TrOCs adsorbed on the sludge were extracted by a solvent extraction method described by Wijekoon et al. (2013). The sludge samples were freeze-dried using a Freeze Dryer (Alpha 12 LD plfx, Christ GmbH, Germany) and then ground to powder. The sludge powder was subjected to ultrasonic solvent extraction with methanol and a blend of methanol and dichloromethane $(1: 1, \mathrm{v} / \mathrm{v})$. Subsequently, the extracted solution was diluted to $500 \mathrm{~mL}$ with Milli-Q water for SPE and then analysed by a GC-MS system as described above. The TrOC concentrations in the sludge were expressed as nanogram TrOC per gram of dry sludge.

\section{Results and discussion}

\subsection{Basic performance}

\subsubsection{Organic and nutrient removal}

The removal of TOC by the control-MBR was high and stable at approximately $99 \%$ over the experimental period (Fig. 1a). On the other hand, the TOC removal by the saline-MBR fluctuated slightly as the salinity loading increased (Fig. 1a). When the salt concentration was lower than $10 \mathrm{~g} \mathrm{NaCl} / \mathrm{L}$, the TOC removal by the saline-MBR was similar to that of the control. The results suggest that salinity build-up at low salt concentration $(<10 \mathrm{~g} \mathrm{NaCl} / \mathrm{L})$ may not pose a significant impact on the removal of organics by MBR. However, the TOC removal by the saline-MBR decreased to around $80 \%$ when the salinity was higher than $10 \mathrm{~g}$ $\mathrm{NaCl} / \mathrm{L}$. This decrease was probably due to the inhibitory effect of high salinity on the biomass, resulting in cell plasmolysis and/or loss of metabolic activity (Yogalakshmi and Joseph, 2010; Johir et al., 2013). Nevertheless, the removal efficiency recovered to approximately $99 \%$ when the salt concentration was maintained at $10 \mathrm{~g} \mathrm{NaCl} / \mathrm{L}$ for two weeks. The recovery could be attributed to the biomass adaptation to the high salinity 
condition (Hong et al., 2013). Small variations in TOC removal by the saline-MBR were also observed during the increase of salinity loading from 10 to $16.5 \mathrm{~g} \mathrm{NaCl} / \mathrm{L}$.

The removal behaviour of TN differed remarkably from TOC removal in response to salinity build-up (Fig. 1a). TN removal by the control-MBR fluctuated in the range of $20-40 \%$ during the experiment. Similar fluctuation was also observed by Nguyen et al. (2012). Given the absence of denitrification under the aerobic conditions applied in this study, the TN removal probably occurred via the conversion of soluble organic substances into insoluble biomass in MBRs (Nghiem et al., 2009; Nguyen et al., 2012). However, the removal of TN by the salineMBR reduced from approximately $23 \%$ to nearly $2.5 \%$ with increasing $\mathrm{NaCl}$ concentration from 0 to $3 \mathrm{~g} / \mathrm{L}$. The reduction was possibly due to the release of lysed cell constituents at elevated salinity (Lefebvre et al., 2005). Nonetheless, the TN removal by the saline-MBR was observed to gradually level off at around $10 \%$ though the $\mathrm{NaCl}$ loading was increased up to $16.5 \mathrm{~g} / \mathrm{L}$.

\section{[FIGURE 1]}

The removal of $\mathrm{NH}_{4}{ }^{+}-\mathrm{N}$ in MBR appeared more sensitive to salinity build-up (Fig. 1b). Given the effective nitrification process in the bioreactor, the control-MBR could constantly remove approximately $99 \%$ of $\mathrm{NH}_{4}{ }^{+}-\mathrm{N}$ over the entire experimental period. However, the removal of $\mathrm{NH}_{4}{ }^{+}-\mathrm{N}$ by the saline-MBR decreased markedly from almost $100 \%$ to $38 \%$ when the $\mathrm{NaCl}$ concentration increased up to $6 \mathrm{~g} / \mathrm{L}$. This observation is consistent with previous studies where high salinity has been reported to adversely affect the nitrification process through inhibiting the metabolic activity and growth rate of nitrifying bacteria (or nitrifiers) during biological treatment (Moussa et al., 2006; Yogalakshmi and Joseph, 2010). Similar to the variations in removal of both $\mathrm{TOC}$ and $\mathrm{TN}, \mathrm{NH}_{4}{ }^{+}-\mathrm{N}$ removal in the saline-MBR gradually improved and remained at nearly $80 \%$ from day 38 onward, even though the $\mathrm{NaCl}$ loading was continuously increased to $16.5 \mathrm{~g} / \mathrm{L}$. Once again, the gradual increase of the ammonium removal by the saline-MBR could be attributed to the microbial adaptation to the hypesalinity condition (Zhang et al., 2014).

Some adverse impact of salinity build-up on the removal of phosphate was also observed (Fig. 1b). During the experimental period, phosphate removal by the control-MBR was in the 
range of 20-30\%, which is in accordance with literature reports (Yogalakshmi and Joseph, 2010; Hong et al., 2013). Hong et al. (2013) concluded that the phosphorous accumulating organisms (PAOs) could utilize phosphorous for cell synthesis and energy transport, resulting in $10-30 \%$ of phosphate removal during biological treatment. However, no or little phosphate was removed in the saline-MBR with the $\mathrm{NaCl}$ concentration in the range of 4-15 g/L (Fig. 1b). A low phosphate removal at elevated salinity was also observed by Uygur (2006) who suggested that the PAOs could lose phosphorous uptake capability under saline stress. Additionally, the release of phosphorous from unmetabolized substances at high salinity could be another reason for the decreased phosphate removal (Lester and Birkett, 1999). Interestingly, the removal of phosphate by the saline-MBR increased and then was maintained at around 10\% with stabilized salinity loading of $16.5 \mathrm{~g} \mathrm{NaCl} / \mathrm{L}$ (Fig. 1b). This increase may be due to the utilization of phosphorous by halophilic bacteria under the hypesaline condition (Lay et al., 2010). Microbial community analysis and/or specific tests for halophilic bacteria would be required to validate this hypothesis; however, that is beyond the scope of this study.

\subsubsection{Biomass properties}

Notable increases in the content of SMP (from 66 to $536 \mathrm{mg} / \mathrm{L}$ ) and EPS (from 32 to $83 \mathrm{mg} / \mathrm{g}$ MLVSS) with increasing salinity loading were observed in the saline-MBR (Fig. 2). The result is in good agreement with previous studies (Laspidou and Rittmann, 2002; Yogalakshmi and Joseph, 2010). The high concentration of SMP and EPS at elevated salinity may be attributed to the autolysis of cells and secretion of organic cellular constituents as well as the accumulation of unmetabolised and/or intermediate products derived from the incomplete degradation of organic substances (Laspidou and Rittmann, 2002). Additionally, the increased concentration of monovalent cations (i.e., $\mathrm{Na}^{+}$) could weaken the intrapolymer bridges and thus result in floc breakdown and release of EPS (Wang et al., 2009). It is noteworthy that the EPS content of the saline-MBR gradually decreased to that of the control system (approximately $50 \mathrm{mg} / \mathrm{g}$ MLVSS) by the end of the experimental period (Fig. 2a). The decreased EPS content was probably because of the increased solubility of EPS fractions (e.g., protein and carbohydrate) at high salinity (Zhang et al., 2014). Thus, a more dramatic increase in the SMP content was observed when the $\mathrm{NaCl}$ loading was stabilized at $16.5 \mathrm{~g} / \mathrm{L}$. 


\section{[FIGURE 2]}

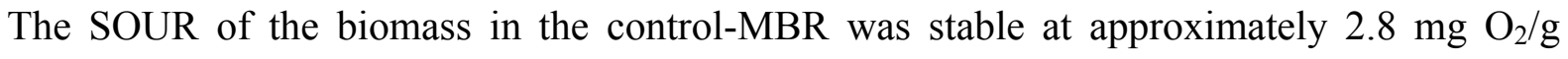
MLVSS $h$ during the experiment. However, a lower SOUR value (2-2.5 $\mathrm{mg} \mathrm{O}_{2} / \mathrm{g}$ MLVSS $\mathrm{h}$ ) was observed in the saline-MBR with increasing the $\mathrm{NaCl}$ concentration (Supplementary Data, Fig. S2). This observation is consistent with previous studies (Lay et al., 2010), confirming the adverse impact of salinity build-up on the microbial activity during biological treatment.

\subsubsection{Membrane fouling propensity}

The TMP profile of the control-MBR was low and stable during the experiment, while that of the saline-MBR increased markedly at enhanced salinity (Fig. 3). The negligible increase in TMP with operating time in the control-MBR was because of the low permeate flux (3.5 $\left.\mathrm{L} / \mathrm{m}^{2} \mathrm{~h}\right)$ and MLSS concentration $(4.8 \pm 0.2 \mathrm{~g} / \mathrm{L})$ applied in this study. Thus, no significant membrane fouling occurred in the control-MBR over the experimental period. By contrast, the TMP of the saline-MBR climbed rapidly as the salt concentration increased, indicating the occurrence of severe membrane fouling. The notable membrane fouling was probably due to the compaction and cohesion of a sludge layer on the membrane surface (Supplementary Data, Fig. S3). Indeed, it is well established that the response of biomass to saline stress can promote the release of SMP and EPS, leading to severe membrane fouling (Zhang et al., 2014). Additionally, salinity increase could lead to an increase in mixed liquor viscosity and a reduction in oxygen solubility, thus exacerbating membrane fouling in MBRs (Lay et al., 2010). Membrane cleaning was conducted for the saline-MBR on day 31 when the TMP reached $23 \mathrm{kPa}$.

\section{[FIGURE 3]}

Similar variations in SMP and TMP at elevated salinity were observed for the saline-MBR (Fig. 2a and 3). This observation is in line with previous studies where the strongly negative correlation between membrane permeability and SMP content has been widely demonstrated (Reid et al., 2006; Wang et al., 2009; Hai et al., 2011). Given the direct exposure of the membrane to SMP in the bulk mixed liquor, the SMP fractions (e.g. protein and 
carbohydrate) exerted greater influence on membrane permeability than EPS (Reid et al., 2006).

\subsection{Trace organic chemical removal}

\subsubsection{General removal behaviour}

It has been reported that the removal of TrOCs by MBRs could be assessed by a qualitative predictive framework based on their hydrophobicity and molecular structure (Tadkaew et al., 2011; Wijekoon et al., 2013). According to this scheme, the 31 TrOCs investigated here could be classified into hydrophobic (i.e., $\log \mathrm{D}_{\mathrm{pH}} 7>3$ ) and hydrophilic (i.e., $\log \mathrm{D}_{\mathrm{pH}} 7<$ 3 ) groups. All hydrophobic compounds in this study could be consistently removed over $90 \%$ by both control- and saline-MBRs with the exception of $17 \alpha$-ethynylestradiol (Fig. 4 and 5). The high removal of these chemicals was probably due to their effective sorption onto the activated sludge, which could facilitate their biodegradation in some cases (Tadkaew et al., 2011). By contrast, the removal of hydrophilic compounds varied markedly in both MBR systems (Fig. 4). The significant variation in the removal of these chemicals in MBRs has been widely demonstrated in previous studies (Visvanathan et al., 2005; Nguyen et al., 2012). Given the weak adsorption of these chemicals onto the biomass, their removal during MBR treatment is largely determined by their intrinsic biodegradability (Tadkaew et al., 2011; Wijekoon et al., 2013). With the presence of strong electron donating functional groups such as amine and hydroxyl groups (Supplementary Data, Table S1), certain chemicals (e.g. salicylic acid, ibuprofen enterolactone and pentachlorophenol) could be removed completely. However, removal efficiency of less than $40 \%$ was observed for all TrOCs (i.e. clofibric acid, diclofenac, propoxur, carbamazepine, and atrazine) that are known to be persistent activated sludge treatment. This low removal efficiency can be attributed to either the absence of strong electron functional groups or the presence of strong electron withdrawing functional groups, such as chlorine, amide and nitro groups, in their molecular structures (Supplementary Data, Table S1).

\section{[FIGURE 4]}

\section{[FIGURE 5]}

\subsubsection{Impact of salinity build-up on TrOC removal}


No discernible difference between the control- and saline-MBRs was observed with regard to the removal of all hydrophobic compounds with $17 \alpha$-ethynylestradiol being the exception (Fig. 4). The removal of $17 \alpha$-ethynylestradiol by the saline-MBR decreased remarkably with the elevated salinity (Fig. 5), which might be due to the inhibitory effects of high salinity on the microorganisms that specifically biodegrade $17 \alpha$-ethynylestradiol.

Unlike the hydrophobic TrOCs, impacts of salinity build-up on the removal of hydrophilic TrOCs varied significantly (Fig. 4). Of the 18 hydrophilic TrOCs selected here, consistent and high removal (above 90\%) by both control- and saline-MBRs was observed for six compounds, namely, salicylic acid, ibuprofen, enterolactone, estriol, formonoetin and pentachlorophenol. The result is consistent with that reported by Tadkaew et al. (2013) who investigated the effect of salt shock load on the TrOC removal, suggesting that salinity buildup had negligible impact on the removal of these readily biodegradable chemicals during MBR treatment. The independence of these chemicals to the elevated salinity could also be evidenced by the small standard deviation of nine removal measurements in the saline-MBR at different $\mathrm{NaCl}$ loadings. By contrast, the removals of other hydrophilic compounds by the saline-MBR were lower than those by the control-MBR. A notable decrease in the removal of seven hydrophilic chemicals (i.e. metronidazole, fenoprop, ametryn, gemifibrozil, naproxen, ketoprofen and primidone) with increase in the $\mathrm{NaCl}$ concentration was observed in the saline-MBR (Fig. 5). The salt-dependent removals of these chemicals could also explain their relatively large standard deviation (20-40\%) observed in Fig. 4, which confirmed that the disrupted metabolic activity at elevated salinity could be responsible for the reduced removals of these chemicals.

\subsubsection{Impact of salinity build-up on TrOC adsorption on sludge}

Various levels of TrOC adsorption onto the sludge were observed in the control-MBR (Fig. 6). Generally, the concentrations of hydrophilic TrOCs in the sludge phase were relatively low with four chemicals (i.e. fenoprop, amitriptyline, pentachlorophenol and ametryn) being the exceptions (Fig. 6a). The low accumulation of hydrophilic compounds in the sludge phase has been reported by Wijekoon et al. (2013). By contrast, the relatively high concentrations of these four chemicals in the biosolids were due to their moderate hydrophobicity and/or less biodegradability. Of all hydrophilic TrOCs selected, amitriptyline exhibited the highest 
concentration in the sludge phase. Such a marked accumulation in the biosolids could be attributed to the combined hydrophobic and electrostatic interactions between amitriptyline and the activated sludge (Stevens-Garmon et al., 2011). Interestingly, the residual concentration of most hydrophobic TrOCs (e.g. oxybenzone, 17 $\alpha$-ethynylestradiol and 17 $\beta$ estradiol) was low in the sludge phase (Fig. 6b). This observation is also in line with Wijekoon et al. (2013) who attributed the low residual concentrations of these hydrophobic compounds to their high biodegradability.

\section{[FIGURE 6]}

Salinity build-up had negligible impact on residual accumulation of TrOCs in the sludge phase except for a few chemicals (i.e. salicylic acid, ketoprofen, naproxen, primidone, ibuprofen, propoxur, diclofenac, gemfibrozil, and 17 $\alpha$-ethynylestradiol) (Fig. 6). The concentration of these chemicals in the biosolids increased at high salinity, which correlated well to the decrease of their overall removals with the increasing $\mathrm{NaCl}$ concentration (Fig. 4 and 5). It has been reported that biodegradation and hydrophobicity are two important factors responsible for the adsorption of TrOCs onto the sludge (Wijekoon et al., 2013). Thus, the increased accumulation of these chemicals in the sludge phase could result from the disrupted biodegradation at elevated salinity. It is also noteworthy that the hydrophobicity of the activated sludge gradually increased with increasing the $\mathrm{NaCl}$ loading (Supplementary Data, Fig. S4). Thus, the high hydrophobic interaction between these chemicals and the activated sludge at elevated salinity could be another reason for the increase in their concentration in the biosolids.

\section{Conclusion}

Results reported in this study indicate that salinity build-up in MBRs could adversely affect the microbial activity and thus lower the system performance regarding the removal of nutrients, organic matters, and some hydrophilic TrOCs. However, the removal of hydrophobic TrOCs in MBR was not affected by salinity build-up. Similarly, salinity increase did not significantly affect the residual accumulation of TrOCs in the sludge phase. In addition, the concentrations of both SMP and EPS in MBR increased at elevated salinity condition, which could result in severe membrane fouling. 


\section{Acknowledgement}

This research was supported under Australian Research Council's Discovery Project funding scheme (project DP140103864). The authors would like to thank the Chinese Scholarship Council and the University of Wollongong for the PhD scholarship support to Wenhai Luo.

\section{Reference}

1. Achilli, A., Cath, T.Y., Marchand, E.A., Childress, A.E., 2009. The forward osmosis membrane bioreactor: A low fouling alternative to MBR processes. Desalination 239, 1021.

2. APHA. 2005. Standard methods for the examination of water and wastewater, American Public Health Association. New York.

3. Choi, J.H., Dockko, S., Fukushi, K., Yamamoto, K., 2002. A novel application of a submerged nanofiltration membrane bioreactor (NF MBR) for wastewater treatment. Desalination 146, 413-420.

4. Choi, J.H., Lee, S.H., Fukushi, K., Yamamoto, K., 2007. Comparison of sludge characteristics and PCR-DGGE based microbial diversity of nanofiltration and microfiltration membrane bioreactors. Chemosphere 67, 1543-1550.

5. Elimelech, M., Phillip, W.A., 2011. The future of seawater desalination: Energy, technology, and the environment. Science 333, 712-717.

6. Hai, F.I., Tessmer, K., Nguyen, L.N., Kang, J., Price, W.E., Nghiem, L.D., 2011. Removal of micropollutants by membrane bioreactor under temperature variation. J. Membr. Sci. 383, 144-151.

7. Hai, F.I., Yamamoto, K., Lee, C.H. 2014. Membrane Biological Reactors: Theory, Modeling, Design, Management and Applications to Wastewater Reuse. IWA Publishing, London.

8. Hong, J.M., Li, W.B., Lin, B., Zhan, M.C., Liu, C.D., Chen, B.Y., 2013. Deciphering the effect of salinity on the performance of submerged membrane bioreactor for aquaculture of bacterial community. Desalination 316, 23-30.

9. Johir, M.A.H., Vigneswaran, S., Kandasamy, J., BenAim, R., Grasmick, A., 2013. Effect of salt concentration on membrane bioreactor (MBR) performances: Detailed organic characterization. Desalination 322, 13-20. 
10. Laspidou, C.S., Rittmann, B.E., 2002. A unified theory for extracellular polymeric substances, soluble microbial products, and active and inert biomass. Water Res. 36, 2711-2720.

11. Lay, W.C.L., Liu, Y., Fane, A.G., 2010. Impacts of salinity on the performance of high retention membrane bioreactors for water reclamation: A review. Water Res. 44, 21-40.

12. Lefebvre, O., Vasudevan, N., Torrijos, M., Thanasekaran, K., Moletta, R., 2005. Halophilic biological treatment of tannery soak liquor in a sequencing batch reactor. Water Res. 39, 1471-1480.

13. Lester, J.N., Birkett, J.W. 1999. Microbiology and Chemistry for Environmental Scientists and Engineers. CRC Press, GB.

14. Luo, W., Hai, F.I., Price, W.E., Guo, W., Ngo, H.H., Yamamoto, K., Nghiem, L.D., 2014a. High retention membrane bioreactors: Challenges and opportunities. Bioresour. Technol. 167, 539-546.

15. Luo, Y., Guo, W., Ngo, H.H., Nghiem, L.D., Hai, F.I., Zhang, J., Liang, S., Wang, X.C., 2014b. A review on the occurrence of micropollutants in the aquatic environment and their fate and removal during wastewater treatment. Sci. Total Environ. 473-474, 619641.

16. Moussa, M.S., Sumanasekera, D.U., Ibrahim, S.H., Lubberding, H.J., Hooijmans, C.M., Gijzen, H.J., van Loosdrecht, M.C.M., 2006. Long term effects of salt on activity, population structure and floc characteristics in enriched bacterial cultures of nitrifiers. Water Res. 40, 1377-1388.

17. Nghiem, L.D., Tadkaew, N., Sivakumar, M., 2009. Removal of trace organic contaminants by submerged membrane bioreactors. Desalination 236, 127-134.

18. Nguyen, L.N., Hai, F.I., Kang, J., Price, W.E., Nghiem, L.D., 2012. Removal of trace organic contaminants by a membrane bioreactor-granular activated carbon (MBR-GAC) system. Bioresour. Technol. 113, 169-173.

19. Phattaranawik, J., Fane, A.G., Pasquier, A.C.S., Bing, W., 2008. A novel membrane bioreactor based on membrane distillation. Desalination 223, 386-395. 
20. Reid, E., Liu, X., Judd, S.J., 2006. Effect of high salinity on activated sludge characteristics and membrane permeability in an immersed membrane bioreactor. J. Membr. Sci. 283, 164-171.

21. Stevens-Garmon, J., Drewes, J.E., Khan, S.J., McDonald, J.A., Dickenson, E.R.V., 2011. Sorption of emerging trace organic compounds onto wastewater sludge solids. Water Res. 45, 3417-3426.

22. Tadkaew, N., Hai, F.I., McDonald, J.A., Khan, S.J., Nghiem, L.D., 2011. Removal of trace organics by MBR treatment: The role of molecular properties. Water Res. 45, 24392451.

23. Tadkaew, N., McDonald, J., Khan, S.J., Nghiem, L.D., 2013. Effects of salinity on the removal of trace organic contaminants by membrane bioreactor treatment for water reuse. Desalin. Water Treat. 51, 5164-5171.

24. Tadkaew, N., Sivakumar, M., Khan, S.J., McDonald, J.A., Nghiem, L.D., 2010. Effect of mixed liquor $\mathrm{pH}$ on the removal of trace organic contaminants in a membrane bioreactor. Bioresour. Technol. 101, 1494-1500.

25. Tran, N.H., Urase, T., Ngo, H.H., Hu, J., Ong, S.L., 2013. Insight into metabolic and cometabolic activities of autotrophic and heterotrophic microorganisms in the biodegradation of emerging trace organic contaminants. Bioresour. Technol. 146, 721731.

26. Urase, T., Kagawa, C., Kikuta, T., 2005. Factors affecting removal of pharmaceutical substances and estrogens in membrane separation bioreactors. Desalination 178, 107-113.

27. Uygur, A., 2006. Specific nutrient removal rates in saline wastewater treatment using sequencing batch reactor. Process Biochem. 41, 61-66.

28. Van den Broeck, R., Krzeminski, P., Van Dierdonck, J., Gins, G., Lousada-Ferreira, M., Van Impe, J.F.M., van der Graaf, J.H.J.M., Smets, I.Y., van Lier, J.B., 2011. Activated sludge characteristics affecting sludge filterability in municipal and industrial MBRs: Unraveling correlations using multi-component regression analysis. J. Membr. Sci. 378, 330-338.

29. Visvanathan, C., Thu, L.N., Jegatheesan, V., Anotai, J., 2005. Biodegradation of pentachlorophenol in a membrane bioreactor. Desalination 183, 455-464. 
30. Wang, Z., Wu, Z., Tang, S., 2009. Extracellular polymeric substances (EPS) properties and their effects on membrane fouling in a submerged membrane bioreactor. Water Res. 43, 2504-2512.

31. Weiss, S., Reemtsma, T., 2008. Membrane bioreactors for municipal wastewater treatment - A viable option to reduce the amount of polar pollutants discharged into surface waters? Water Res. 42, 3837-3847.

32. Wijekoon, K.C., Hai, F.I., Kang, J., Price, W.E., Guo, W., Ngo, H.H., Nghiem, L.D., 2013. The fate of pharmaceuticals, steroid hormones, phytoestrogens, UV-filters and pesticides during MBR treatment. Bioresour. Technol. 144, 247-254.

33. Yogalakshmi, K.N., Joseph, K., 2010. Effect of transient sodium chloride shock loads on the performance of submerged membrane bioreactor. Bioresour. Technol. 101, 70547061.

34. Zhang, H., Gao, Z., Zhang, L., Song, L., 2014. Performance enhancement and fouling mitigation by organic flocculant addition in membrane bioreactor at high salt shock. Bioresour. Technol. 164, 34-40.

35. Zhang, X.Q., Bishop, P.L., Kinkle, B.K., 1999. Comparison of extraction methods for quantifying extracellular polymers in biofilms. Water Res. Technol. 39, 211-218. 


\section{FIGURE CAPTIONS}

Fig. 1: Variation of organic and nutrient removal by MBRs. The blue line represents the salt loading procedure for the saline-MBR. Experimental conditions for both the control- and saline-MBRs: HRT of $24 \mathrm{~h}$; SRT of approximately $50 \mathrm{~d}$; DO concentration of $5 \pm 1 \mathrm{mg} / \mathrm{L}$; temperature of $26.0 \pm 0.2{ }^{\circ} \mathrm{C}$.

Fig. 2: Variation of (a) SMP and (b) EPS concentration during MBR operation.

Fig. 3: Variation of TMP profile during MBR operation. Membrane cleaning for the saline-MBR was conducted by ex-situ backwashing with $1 \% \mathrm{NaOCl}$ for $20 \mathrm{~min}$, and then rinsing with deionized water.

Fig. 4: General removal behaviour of TrOCs by the control- and saline-MBRs. The influent concentration of each TrOC was $5 \mu \mathrm{g} / \mathrm{L}$. The compounds were arranged in the increasing order of Log $\mathrm{D}$ values at $\mathrm{pH}=7$. Error bars represent the standard deviation of 11 and 9 measurements in case of the control- and saline-MBR, respectively.

Fig. 5: Effect of salinity build-up on TrOC removal. Salinity build-up simulated by gradually increasing the $\mathrm{NaCl}$ concentration in the saline-MBR from 0 to $16.5 \mathrm{~g} / \mathrm{L}$ with a salinity gradient of $0.5 \mathrm{~g} \mathrm{NaCl} / \mathrm{L}$ per day. Maximum salinity determined by modelling the steady-state salt accumulation in an OMBR system operated under certain conditions. The control-MBR was operated under the same condition but without any $\mathrm{NaCl}$ addition. The influent concentration of each TrOC was $5 \mu \mathrm{g} / \mathrm{L}$.

Fig. 6: Effect of salinity build-up on the residual accumulation of (a) hydrophilic and (b) hydrophobic TrOCs in the sludge phase during MBR operation. The influent concentration of each TrOC was $5 \mu \mathrm{g} / \mathrm{L}$. Error bars represent the standard deviation of 
four and two measurements in case of the control-MBR and the saline one at $\mathrm{NaCl}$ loading of 0 and $16.5 \mathrm{~g} / \mathrm{L}$, respectively.

\section{FIGURES}
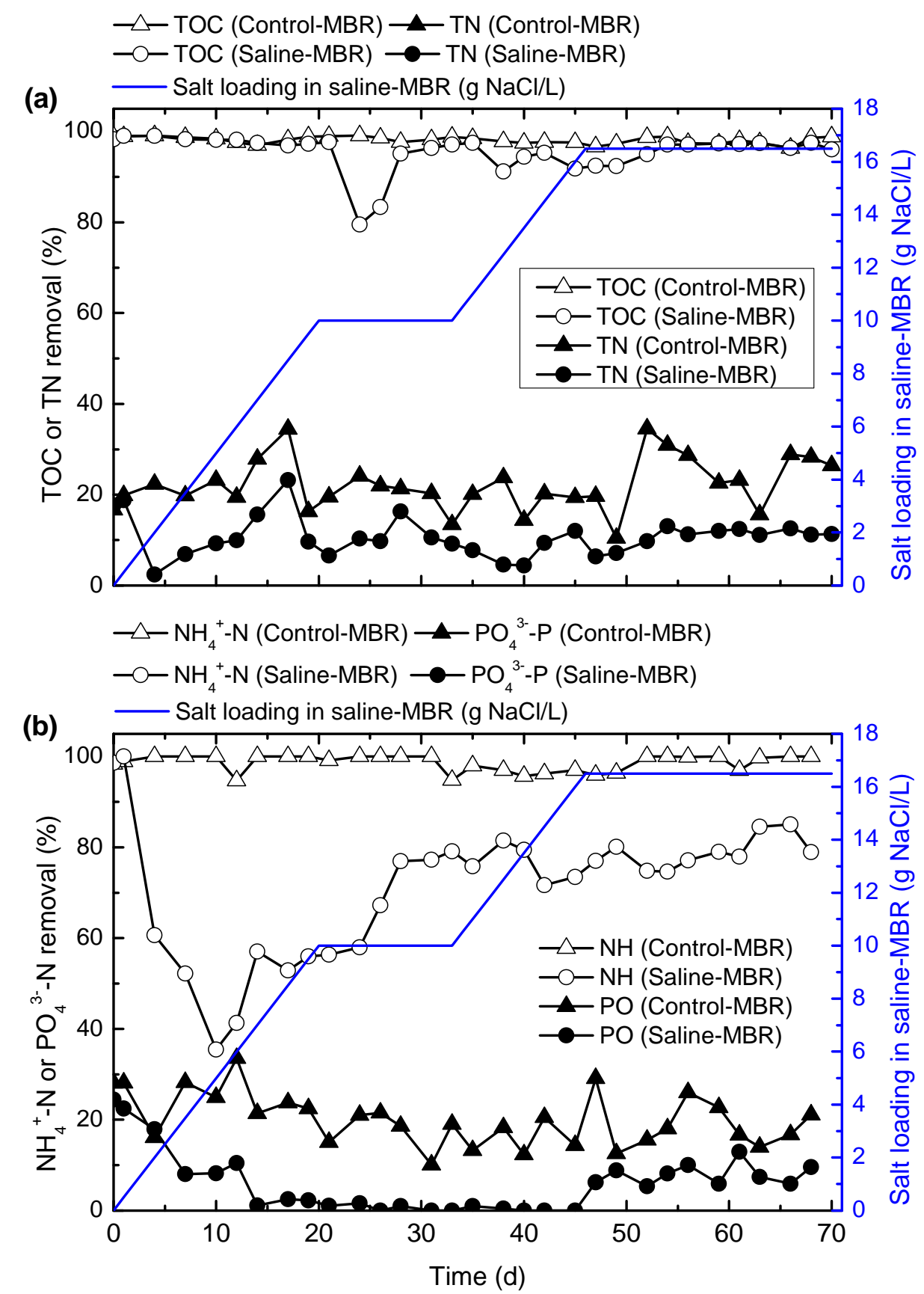

Fig. 1 

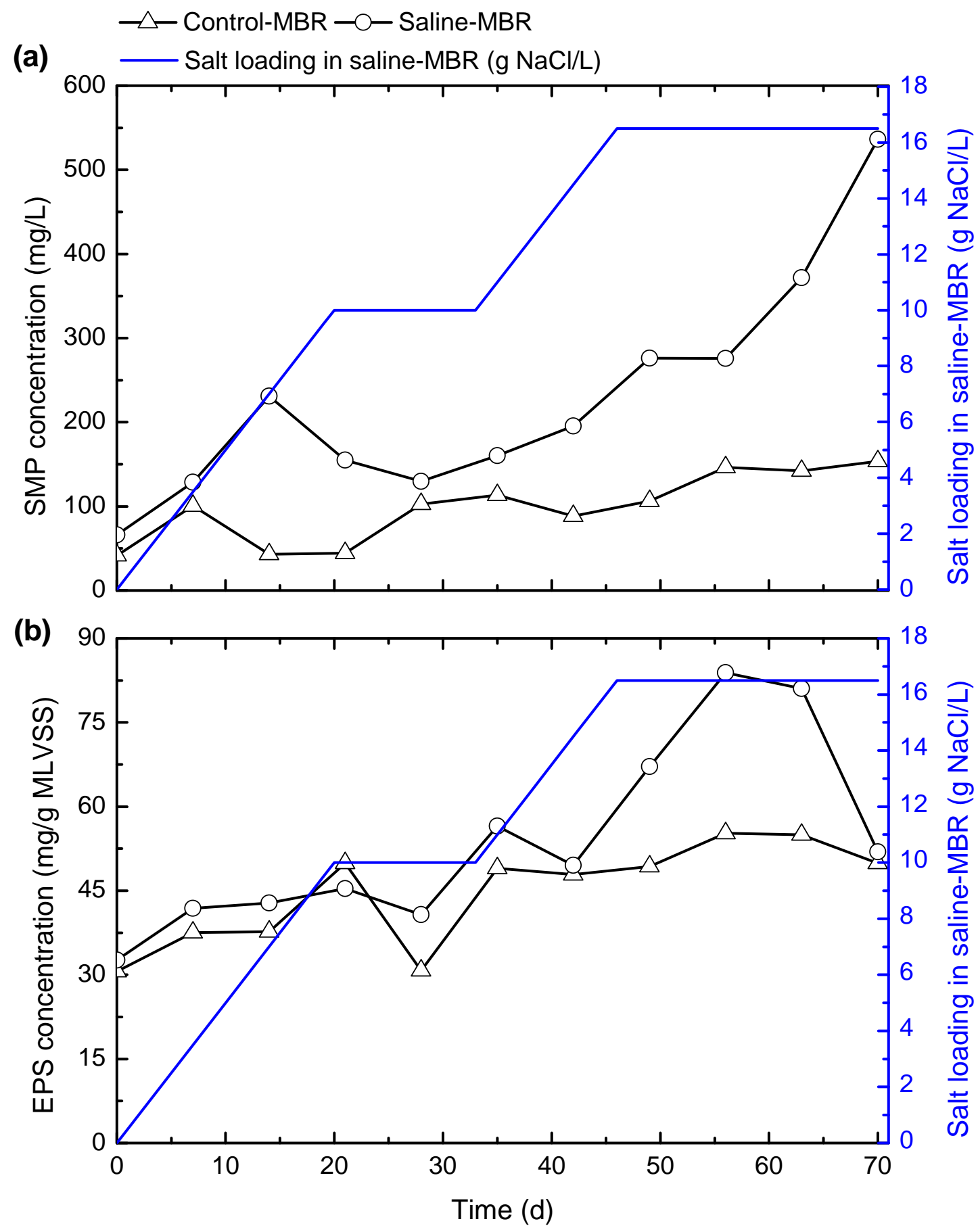

Fig. 2 


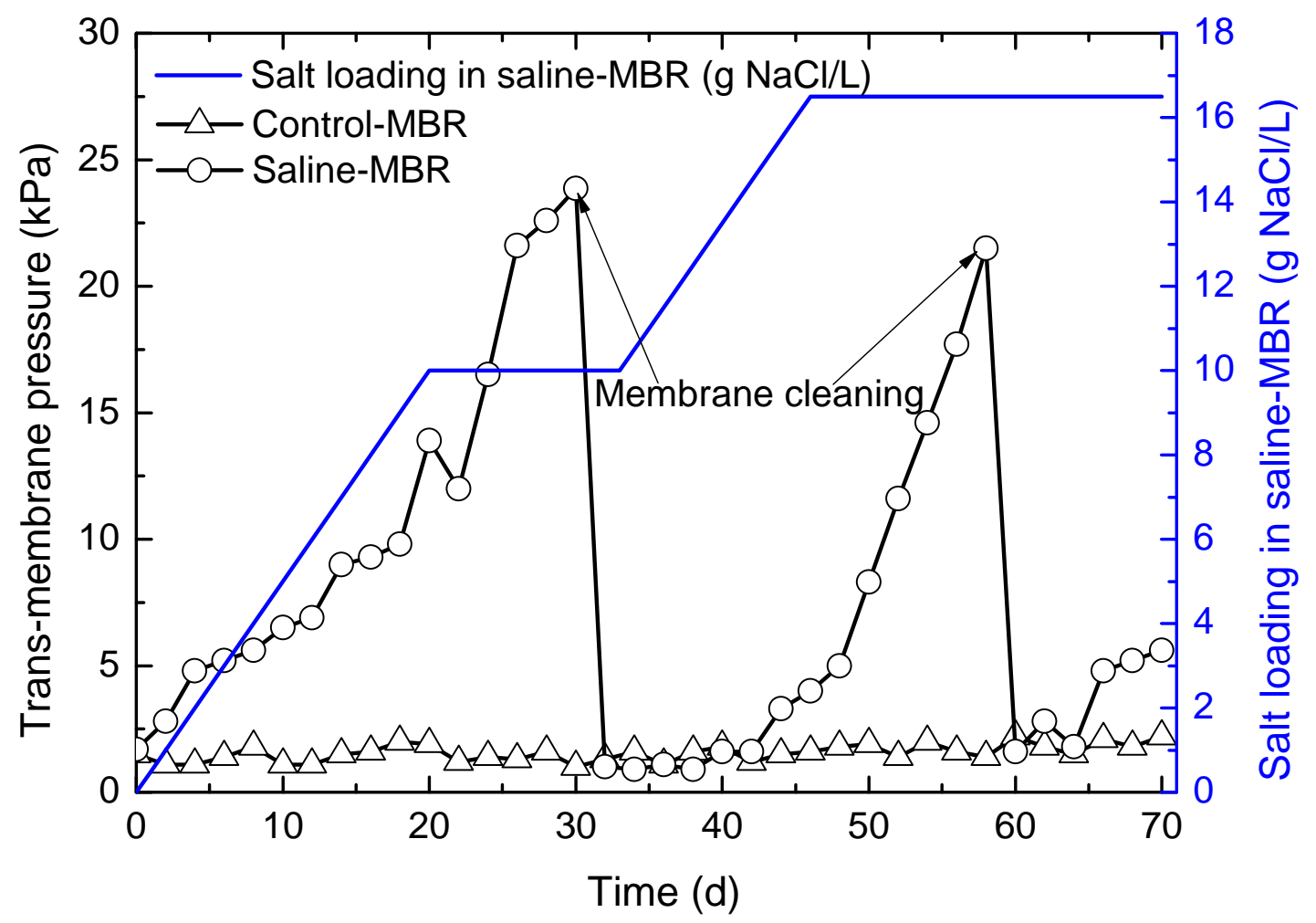

Fig. 3 


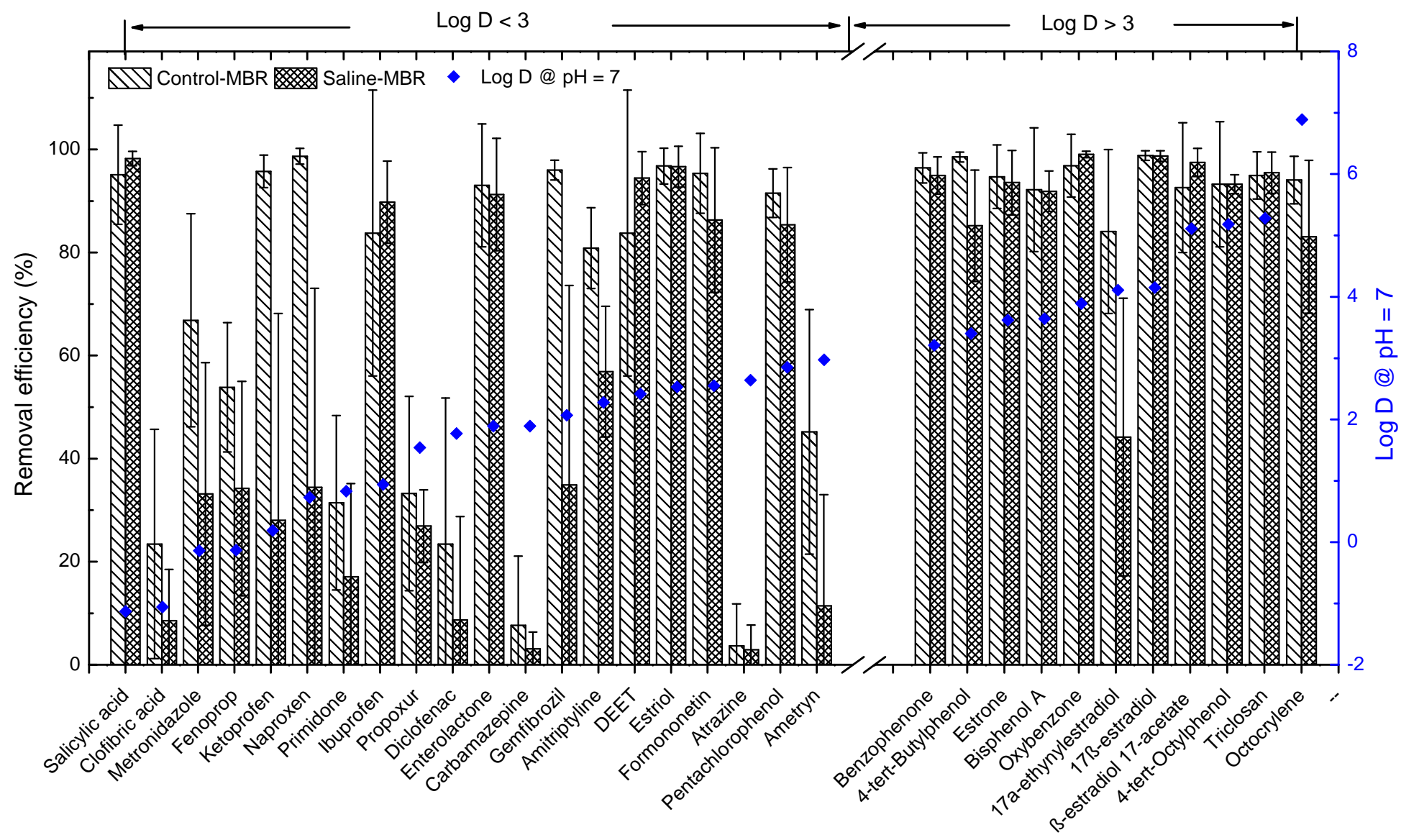

Fig. 4 

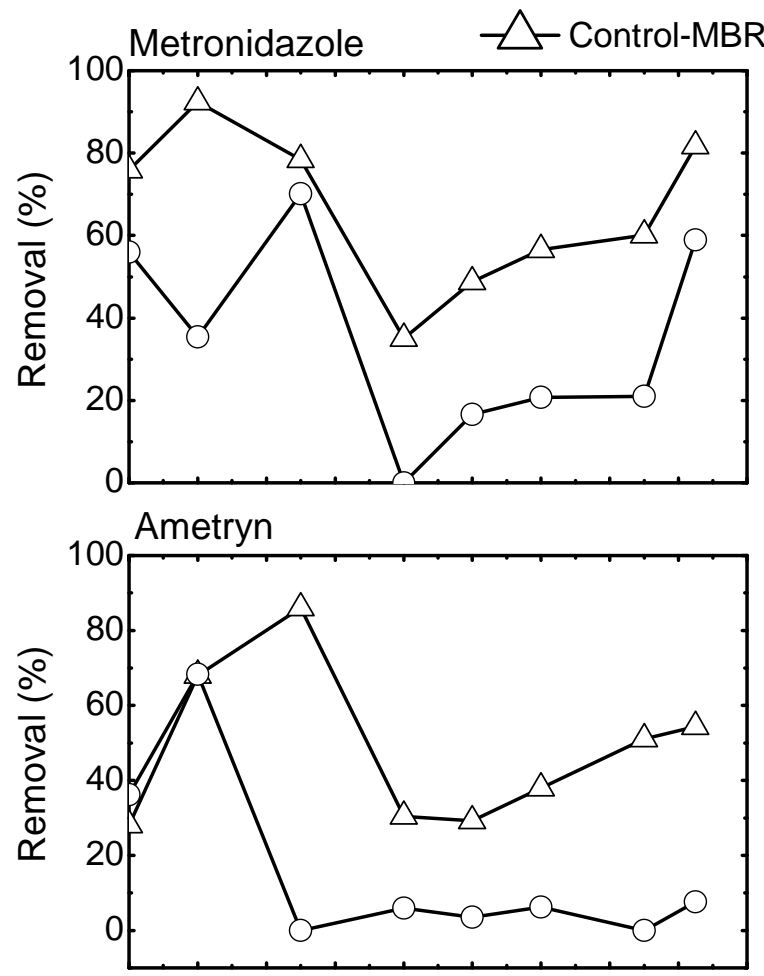

- Saline-MBR

Fenoprop
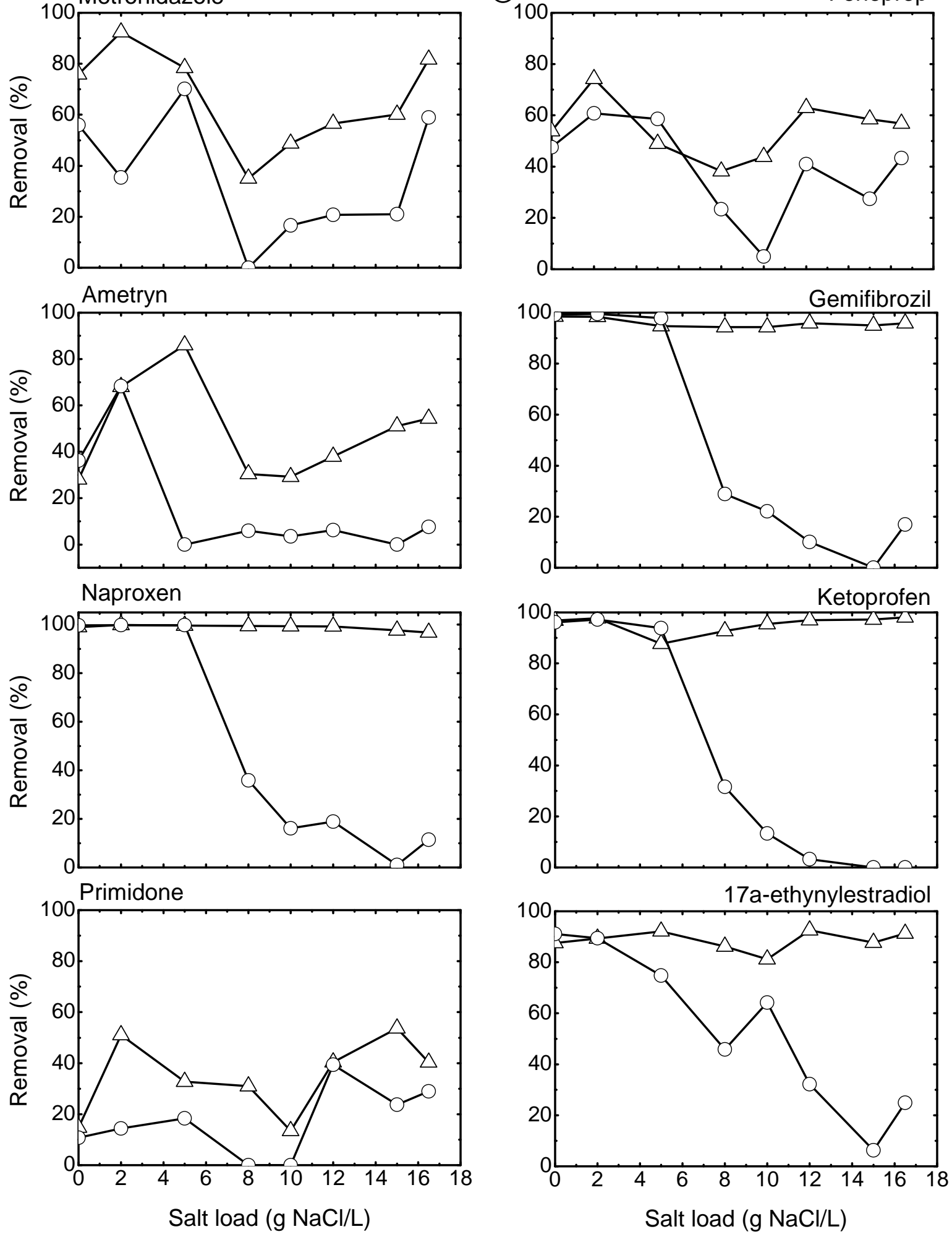

Fig. 5 

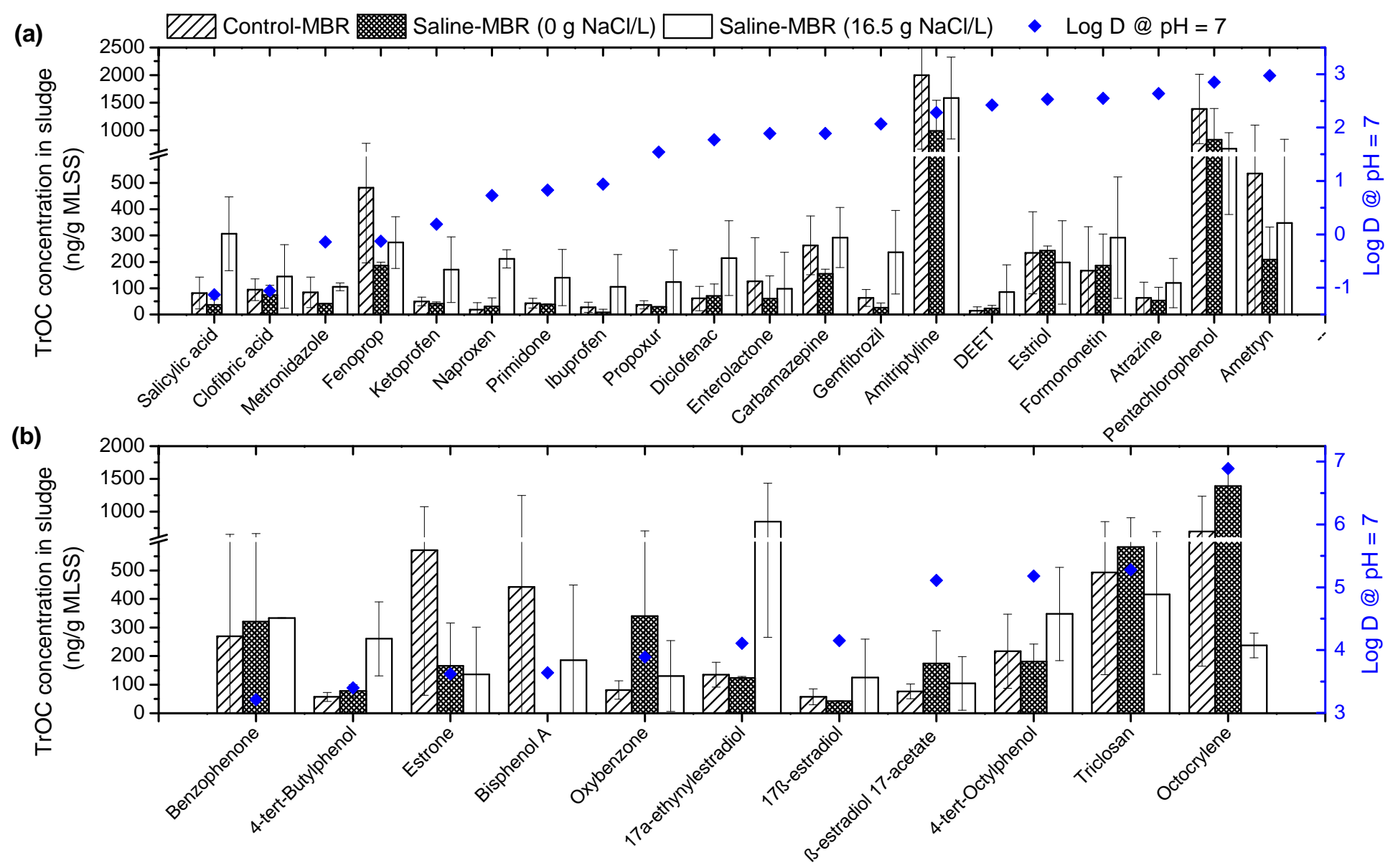

Fig. 6 


\section{SUPPLEMENTARY DATA}

\section{Appendix A. Modelling salt concentration in OMBR under the steady-state condition}

The salt accumulation in the bioreactor remains a challenge to the further development of a novel osmotic membrane bioreactor (OMBR) for wastewater treatment and reuse. During OMBR operation, the salt accumulation could occur due to the effective rejection of salts from the influent by high retention forward osmosis (FO) membranes and the reverse diffusion of solutes from the draw solution. The increased salt concentration could adversely affect microbial activity in the bioreactor and thus deteriorate the membrane and treatment performance of OMBR to some extents.

According to Xiao et al., (2011), the steady-state salinity $\left(C_{m l}\right)$ in OMBR can be determined by:

$C_{m l, \text { stready }}=\frac{S R T}{H R T_{\text {steady }}} C_{\text {in }}+\left(\frac{S R T}{H R T_{\text {steady }}}-1\right) \frac{B}{\mathrm{~A} \beta R_{g} T}$

where, $C_{i n}$ is the salt concentration of the influent; A and B are the water permeability and solute permeability of the rejection layer of the FO membrane, respectively; $\beta$ is the van't Hoff coefficient; $R_{g}$ is the universal gas constant, $T$ is the absolute temperature; $S R T$ is the operating sludge retention time; $H R T_{\text {steady }}$ is the hydraulic retention time at steady state.

Given the gradual decrease of the permeate flux with increasing salinity in the bioreactor; the HRT is time-dependent during OMBR operation. Thus, the $\mathrm{HRT}_{\text {steady }}$ can be determined by the steady-state water flux $\left(J_{v, \text { steady }}\right)$ :

$$
\begin{aligned}
& H R T_{\text {steady }}=\frac{V}{J_{v, \text { steady }} A_{m}} \\
& J_{v, \text { steady }}=K_{m}\left[\ln \left(\frac{\beta R_{g} T C_{d r a w}}{\beta R_{g} T C_{\text {in }}+B / A}\right)-\ln \left(\frac{J_{v, \text { steady }} \times S R T}{H R T_{0} \times J_{0}}\right)\right]
\end{aligned}
$$

where, $V$ is the bioreactor volume; $K_{m}$ is the mass transfer coefficient; $C_{\text {draw }}$ is the concentration of the draw solution; $\mathrm{HRT}_{0}$ is the initial HRT. 
From the above equations, the salt accumulation in OMBR is largely determined by membrane properties (A, $B, K_{m}$ and membrane orientation) and operating conditions $\left(\mathrm{C}_{\text {draw }}\right.$, $\mathrm{C}_{\text {in }}, \mathrm{HRT}_{0}$ and SRT).

In this study, a typical commercial cellular triacetate (CTA) FO membrane (with $\mathrm{A}=$ $2.12 \times 10^{-12} \mathrm{~m} / \mathrm{s} \mathrm{Pa}, \mathrm{B}=1.6 \times 10^{-7} \mathrm{~m} / \mathrm{s}, \mathrm{K}_{\mathrm{m}}=5 \times 10^{-6} \mathrm{~m} / \mathrm{s}$ ) was simulated to operate under the following conditions: the synthetic wastewater salinity $\left(C_{i n}\right)=2 \mathrm{mM} \mathrm{NaCl}$; SRT $=10 \mathrm{~d}$; $\mathrm{HRT}_{0}$ $=9 \mathrm{~h}$; bioreactor volume $(V)=4 \mathrm{~L}$; operating temperature $=26{ }^{\circ} \mathrm{C}$; membrane area $\left(A_{m}\right)=$ $0.03 \mathrm{~m}^{2}$. Thus, the model salt concentration in OMBR at steady state was $16.5 \mathrm{~g} \mathrm{NaCl} / \mathrm{L}$.

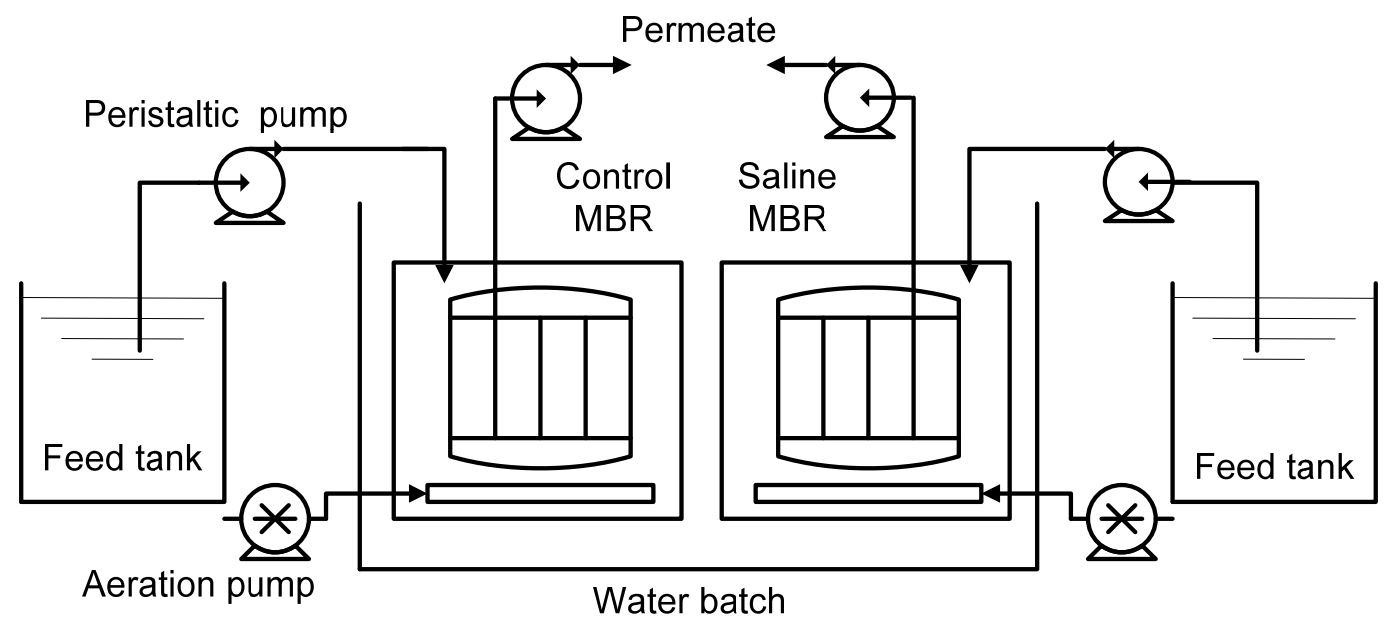

Fig. S1: Schematic diagram of two parallel lab-scale MBR systems. 


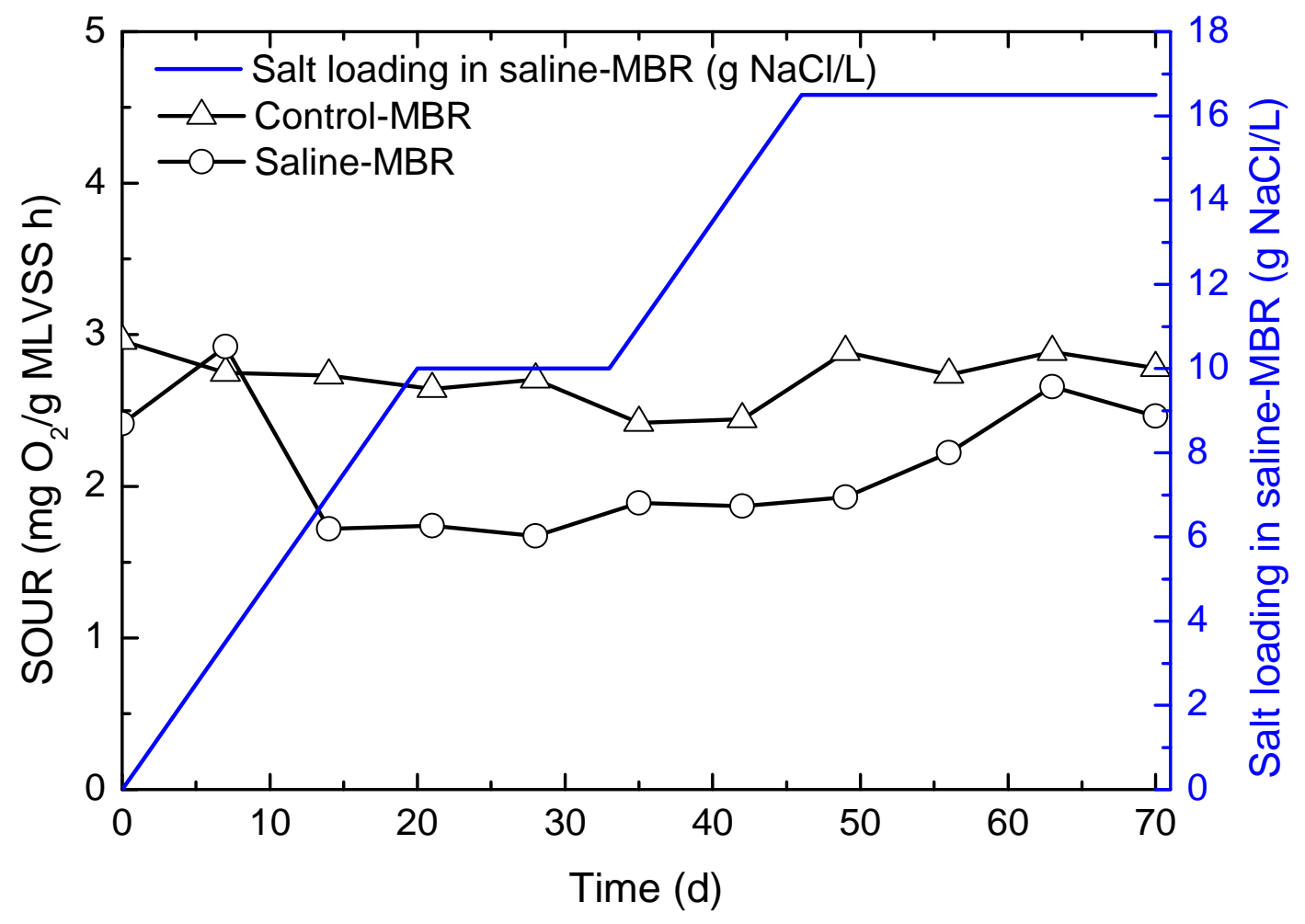

Fig. S2: Variation of the SOUR of the biomass during MBR operation. 

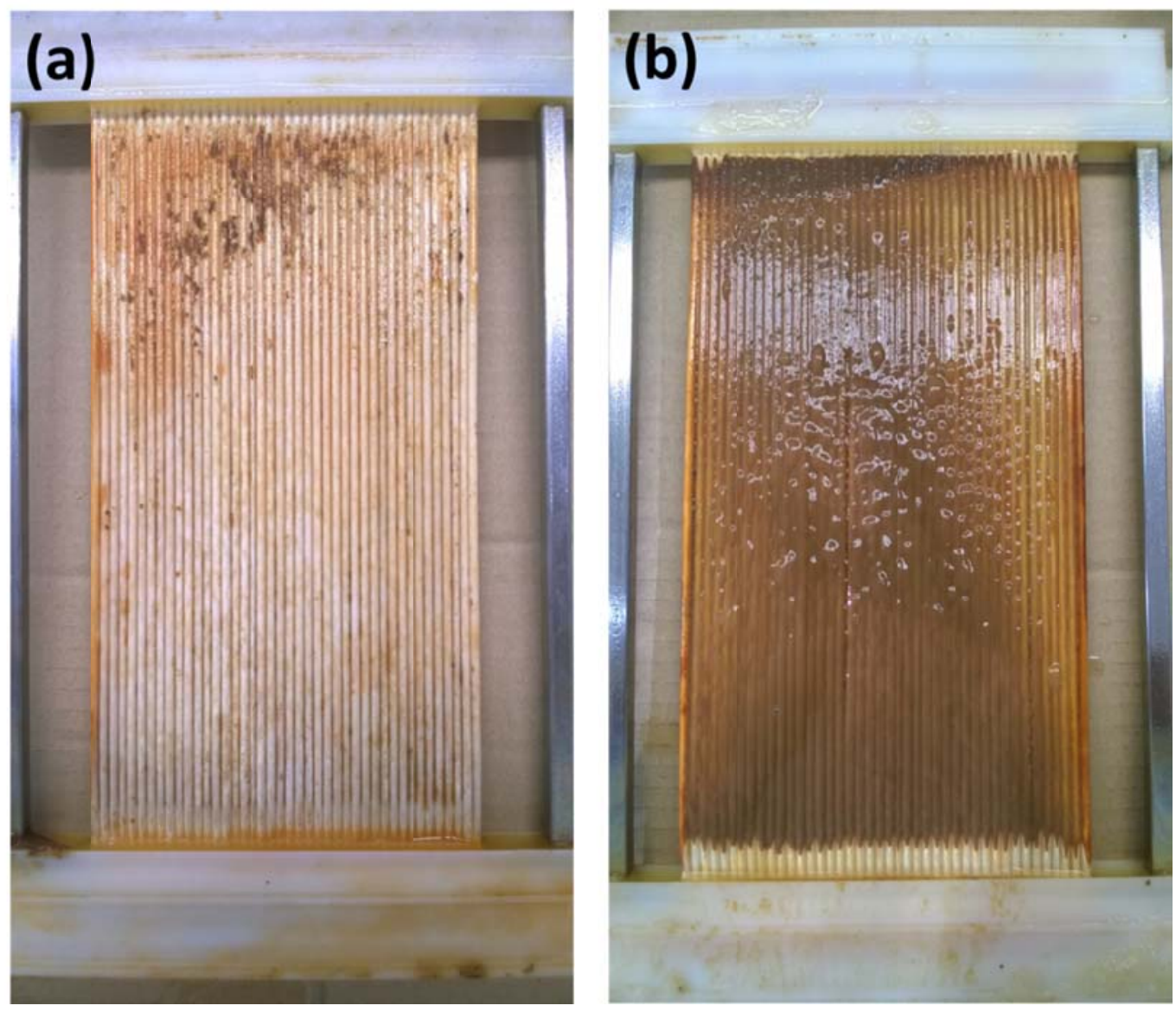

Fig. S3: Photographs of the MF membranes taken from (a) control- and (b) saline-MBR immediately after 70 days of experiment. Experimental conditions: HRT of $24 \mathrm{~h}$; SRT of approximately $50 \mathrm{~d}$; DO concentration of $5 \pm 1 \mathrm{mg} / \mathrm{L}$; temperature of $26.0 \pm 0.2{ }^{\circ} \mathrm{C}$. No membrane cleaning was conducted for the membrane from control-MBR. However, membrane cleaning for saline-MBR was carried out by backwashing with $1 \% \mathrm{NaOCl}$ for 20 min, and then rinsing with deionized water on day 31 when the TMP climbed up to $23 \mathrm{kPa}$. 


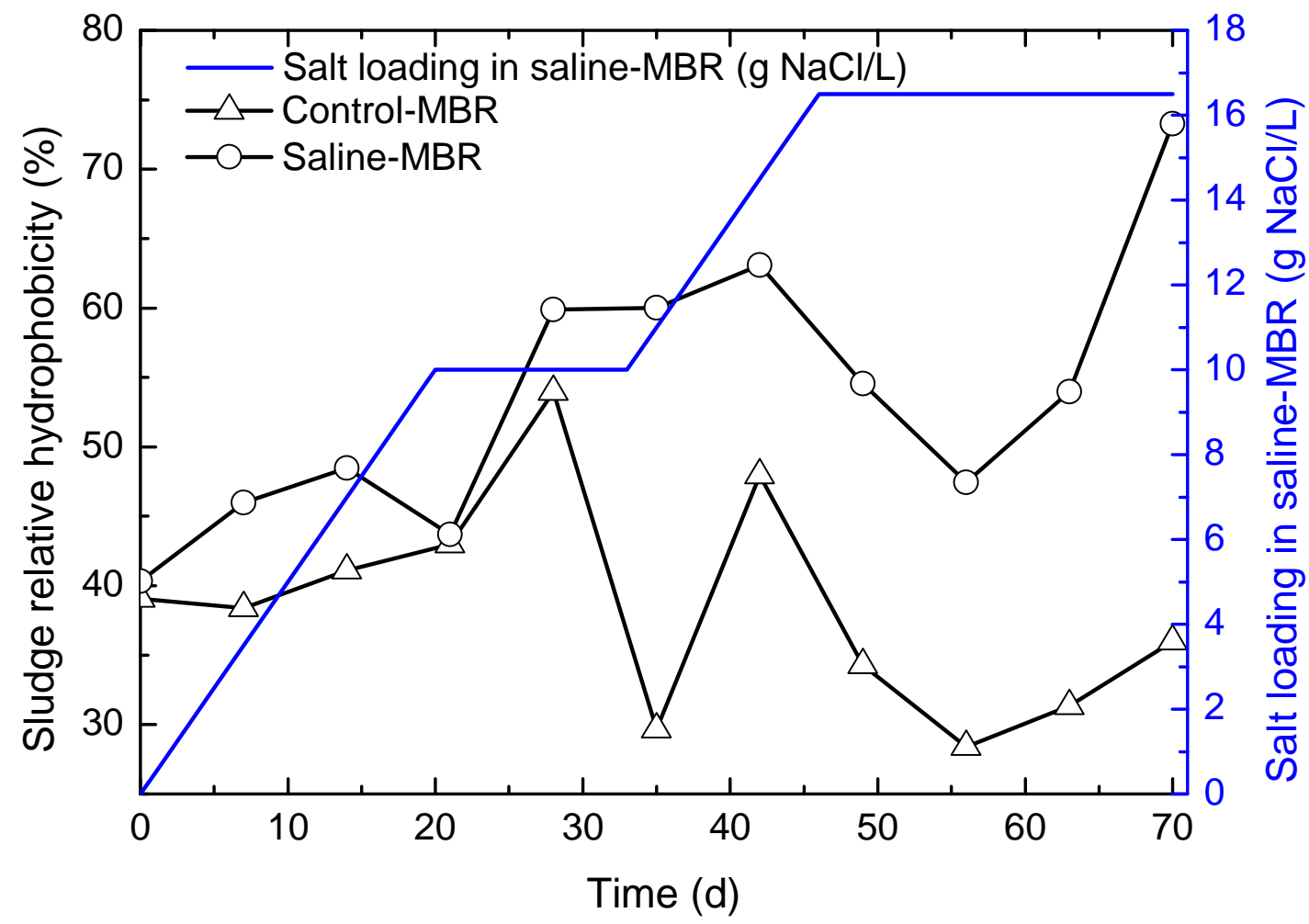

Fig. S4: Variation of sludge relative hydrophobicity during MBR operation. 
Table S1: Physicochemical properties of the selected trace organic chemicals.

\begin{tabular}{|c|c|c|c|c|}
\hline Compounds & $\begin{array}{l}\text { Chemical } \\
\text { formula }\end{array}$ & $\begin{array}{l}\log \mathrm{D} \\
\text { at } \mathrm{pH}=7\end{array}$ & $\begin{array}{l}\text { MW } \\
(\mathrm{g} / \mathrm{mol})\end{array}$ & Chemical structure \\
\hline Salicylic acid & $\mathrm{C}_{7} \mathrm{H}_{6} \mathrm{O}_{3}$ & -1.13 & 138.1 & \\
\hline Clofibric acid & $\mathrm{C}_{10} \mathrm{H}_{11} \mathrm{ClO}_{3}$ & -1.06 & 214.6 & \\
\hline Metronidazole & $\mathrm{C}_{6} \mathrm{H}_{9} \mathrm{~N}_{3} \mathrm{O}_{3}$ & -0.14 & 171.2 & \\
\hline Fenoprop & $\mathrm{C}_{9} \mathrm{H}_{7} \mathrm{Cl}_{3} \mathrm{O}_{3}$ & -0.13 & 269.5 & \\
\hline Ketoprofen & $\mathrm{C}_{16} \mathrm{H}_{14} \mathrm{O}_{3}$ & 0.19 & 254.3 & \\
\hline Naproxen & $\mathrm{C}_{14} \mathrm{H}_{14} \mathrm{O}_{3}$ & 0.73 & 230.3 & \\
\hline Primidone & $\mathrm{C}_{12} \mathrm{H}_{14} \mathrm{~N}_{2} \mathrm{O}_{2}$ & 0.83 & 218.3 & \\
\hline Ibuprofen & $\mathrm{C}_{13} \mathrm{H}_{18} \mathrm{O}_{2}$ & 0.94 & 206.3 & \\
\hline Propoxur & $\mathrm{C}_{11} \mathrm{H}_{15} \mathrm{NO}_{3}$ & 1.54 & 209.2 & \\
\hline Diclofenac & $\mathrm{C}_{14} \mathrm{H}_{11} \mathrm{Cl}_{2} \mathrm{NO}_{2}$ & 1.77 & 296.2 & \\
\hline Enterolactone & $\mathrm{C}_{18} \mathrm{H}_{18} \mathrm{O}_{4}$ & 1.89 & 298.33 & \\
\hline Carbamazepine & $\mathrm{C}_{15} \mathrm{H}_{12} \mathrm{~N}_{2} \mathrm{O}$ & 1.89 & 236.3 & \\
\hline Gemfibrozil & $\mathrm{C}_{15} \mathrm{H}_{22} \mathrm{O}_{3}$ & 2.07 & 250.3 & \\
\hline
\end{tabular}




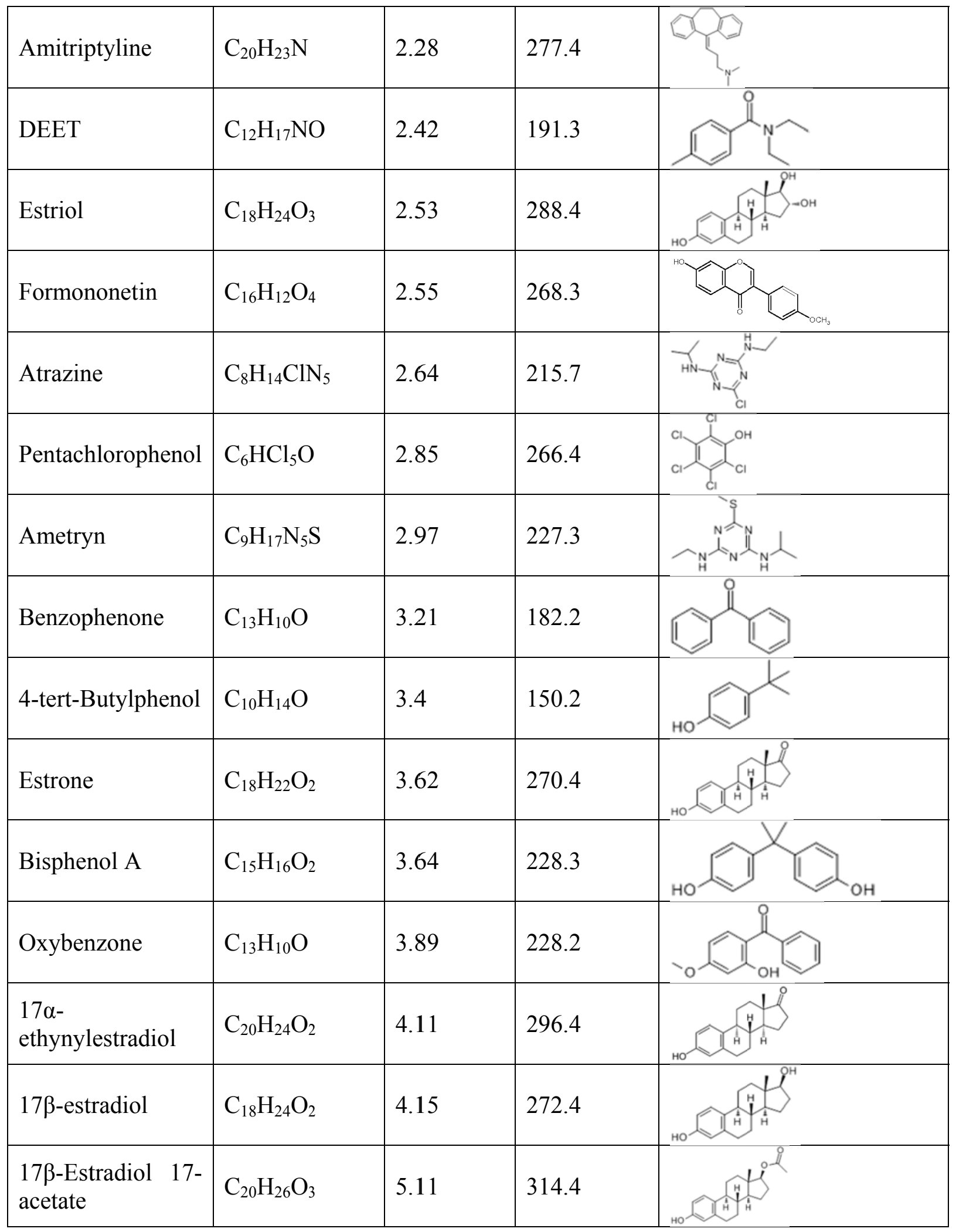




\begin{tabular}{|l|l|l|l|}
\hline 4-tert-Octylphenol & $\mathrm{C}_{14} \mathrm{H}_{22} \mathrm{O}$ & 5.18 & 206.3 \\
\hline Triclosan & $\mathrm{C}_{12} \mathrm{H}_{7} \mathrm{Cl}_{3} \mathrm{O}_{2}$ & 5.28 & 289.5 \\
\hline Octocrylene & $\mathrm{C}_{24} \mathrm{H}_{27} \mathrm{~N}$ & 6.89 & 361.5
\end{tabular}

Source: SciFinder Scholar (ACS) database.

Table S2: Composition of the synthetic wastewater

\begin{tabular}{lll}
\hline Constituent $^{*}$ & Chemical formula & Concentration $(\mathrm{mg} / \mathrm{L})$ \\
\hline Glucose & $\mathrm{C}_{6} \mathrm{H}_{12} \mathrm{O}_{6}$ & 100 \\
Peptone & -- & 100 \\
Potassium dihydrogen phosphate & $\mathrm{KH}_{2} \mathrm{PO}_{4}$ & 17.5 \\
Magnesium sulphate & $\mathrm{MgSO}_{4}$ & 17.5 \\
Sodium acetate & $\mathrm{CH}_{3} \mathrm{COONa}$ & 225 \\
Urea & $\left.\mathrm{NH}_{2}\right)_{2} \mathrm{CO}$ & 35 \\
Ferrous sulphate & $\mathrm{FeSO}_{4}$ & 10 \\
\hline
\end{tabular}

*Synthetic wastewater was used to simulate medium strength municipal sewage (Alturki et al., 2012).

\section{Reference}

Alturki, A., McDonald, J., Khan, S.J., Hai, F.I., Price, W.E., Nghiem, L.D., 2012. Performance of a novel osmotic membrane bioreactor (OMBR) system: flux stability and removal of trace organics. Bioresour. Technol. 113, 201-206.

Xiao, D., Tang, C.Y., Zhang, J., Lay, W.C.L., Wang, R., Fane, A.G., 2011. Modeling salt accumulation in osmotic membrane bioreactors: Implications for FO membrane selection and system operation. J. Membr. Sci. 366, 314-324. 